\title{
Facile Preparation of AT-PEG Polymer and Its Corrosion Inhibition Performance
}

\author{
Jiheng Ding ${ }^{l}$, Wanjun Peng ${ }^{1,2}$, Hongran Zhao ${ }^{1, *}$, Haibin $\mathrm{Yu}^{1, *}$ \\ ${ }^{1}$ Key Laboratory of Marine Materials and Related Technologies, Key Laboratory of Marine Materials \\ and Protective Technologies of Zhejiang Province, Ningbo Institute of Materials Technology and \\ Engineering, Chinese Academy of Sciences, Ningbo 315201, P. R. China; \\ ${ }^{2}$ School of Materials Science and Engineering, Hunan University, Changsha 410000, P. R. China \\ *E-mail: zhaohongran@nimte.ac.cn; haibinyu@nimte.ac.cn
}

doi: $10.20964 / 2017.06 .83$

Received: 25 February 2017 / Accepted: 7 April 2017 / Published: 12 May 2017

\begin{abstract}
Aniline tetramer grafted polyethylene glycol methyl ether (AT-PEG) was obtained from aniline tetramer (AT), polyethylene glycol (PEG) and toluene-2,4-diisocyanate (TDI). Then the structure of AT-PEG was characterized by fourier infrared spectroscopy (FT-IR) and nuclear magnetic resonance $\left({ }^{1} \mathrm{H}\right.$ NMR). The corrosion inhibition performance of AT-PEG for Q235 carbon steel in $1.0 \mathrm{M} \mathrm{HCl}$ solution has been investigated using static weight loss, electrochemical impendence spectroscopy (EIS) and polarization curves, respectively. The results proved that the corrosion inhibition efficiency increased with the increase of AT-PEG, and the corrosion inhibition efficiency of hydrochloric acid solution reached its maximum of $92.50 \%$ in the concentration of $100 \mathrm{mg} / \mathrm{L}$. Here, the results of static weight loss, electrochemical impendence spectroscopy (EIS) and polarization curves were in good agreement with each other.
\end{abstract}

Keywords: Aniline tetramer; Carbon steel; Inhibitor; Static weight loss; Electrochemistry; Hydrochloric acid solution

\section{FULL TEXT}

(C) 2017 The Authors. Published by ESG (www.electrochemsci.org). This article is an open access article distributed under the terms and conditions of the Creative Commons Attribution license (http://creativecommons.org/licenses/by/4.0/). 